Yifei $\mathrm{Wu} \cdot$ Prasanta Datta

\title{
Influence of DNA topology on expression of the tdc operon in Escherichia coli K-12
}

Received: 8 November 1994 / Accepted: 19 January 1995

\begin{abstract}
TdcB activity expressed from the chromosomal gene and LacZ expression from single-copy $t d c-l a c Z$ transcriptional and translational fusions were measured in Escherichia coli strains harboring mutations in the genes encoding DNA gyrase, topoisomerase I and the HU protein. The pattern of $t d c$ operon expression in these mutants suggests that relaxation of supercoiled DNA enhances $t d c$ transcription in vivo.
\end{abstract}

Key words $t d c$ operon - Gene regulation - DNA supercoiling · HU protein - Topoisomerases

The $t d c$ operon of Escherichia coli K-12, which is involved in transport and metabolism of threonine and serine during anaerobic growth, consists of three genes, $t d c A, t d c B$, and $t d c C$, which encode, respectively, a regulatory protein, the enzyme biodegradative (catabolic) threonine dehydratase, and an L-threonine-L-serine permease (Goss et al. 1988; Sumantran et al. 1990). The TdcA polypeptide, with a helix-turn-helix motif typical of DNA-binding proteins, is required for autoregulation of the $t d c A p$ (Ganduri et al. 1993). The efficient in vivo expression of $t d c$ also requires a small polypeptide encoded by $t d c R$, located immediately upstream of $t d c A B C$ in opposite transcriptional orientation (Schweizer and Datta 1989b). Furthermore, both integration host factor (IHF) and the cyclic AMP (cAMP)-catabolite gene activator protein (Crp) complex, which bind to their specific DNA sequences in the $t d c$ promoter, act in concert to activate $t d c$ transcription (Wu and Datta 1992; Wu et al. 1992).

To establish whether the $t d c$ operon is also regulated negatively, we searched for a $t d c$ "repressor" by transforming $\mathrm{MC4} 100(\lambda \mathrm{SH} 241) \quad\left[\lambda \mathrm{SH} 241 \phi\left(t d c A B^{\prime}-{ }^{\prime} l a c Z\right]\right.$ (Ganduri et al. 1993) with an E. coli genomic library, constructed in the expression vector pTrc99A (Pharma-

Communicated by J. F. Lengeler

Y. Wu $\cdot$ P. Datta (区)

Department of Biological Chemistry,

The University of Michigan, Ann Arbor, MI 48109-0606, USA cia) containing a $\mathrm{Kan}^{\mathrm{r}}$ cassette (Schweizer and Datta $1989 \mathrm{~b}$ ), and screening for $\mathrm{Lac}^{-}$transformants on Xgal (5-bromo-4-chloro-3-indolyl- $\beta$-D-galactopyranoside) plates (Miller 1992). From a few such transformants we selected one for isolation and characterization of the plasmid DNA. As shown in Fig. 1, the plasmid pGL3.7, containing a $3.7 \mathrm{~kb} E$. coli DNA insert prevented TdcB expression when introduced into the wild-type DH5 $\alpha \mathrm{F}^{\prime}$ (Hagewood et al. 1994). TdcB expression in other $E$. col $i$ strains including MC4100, W3110, C600R and NM522 was also severely depressed by pGL3.7. Subcloning of various restriction fragments of pGL3.7, followed by transformation of $\mathrm{DH} 5 \alpha \mathrm{F}^{\prime}$, indicated that a $1.3 \mathrm{~kb}$ EcoRV fragment in pGL1.3 encoded a repressor-like activity (Fig. 1).

DNA sequence analysis of the fragment and a GenBank database search revealed that the cloned insert contained, among other sequences, the 270-bp hupA coding region (Kano et al. 1987). That the hupA gene product,

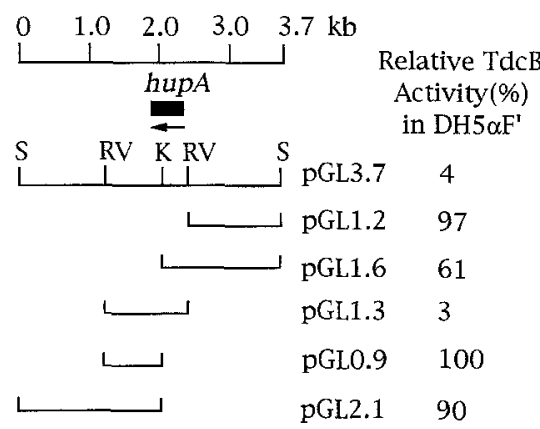

Fig. 1 Restriction map of the $h u p A$ region and TdcB expression in DH $5 \alpha F^{\prime}$ harboring various restriction fragments cloned into the pTrc99A vector, yielding the pGL series of plasmids. Abbreviations: S, Sau3A; RV, EcoRV; K, KpnI. Threonine dehydratase activities of cells transformed with the indicated plasmids were assayed after anaerobic incubation in TYE medium as described (Hobert and Datta 1983). The specific activity is expressed relative to the value obtained with $\mathrm{DH} 5 \alpha \mathrm{F}^{\prime}$ harboring only the pTrc99A vector (3799 $\mathrm{nmol}$ of $\alpha$-ketobutyrate formed per min per $\mathrm{mg}$ of protein) 


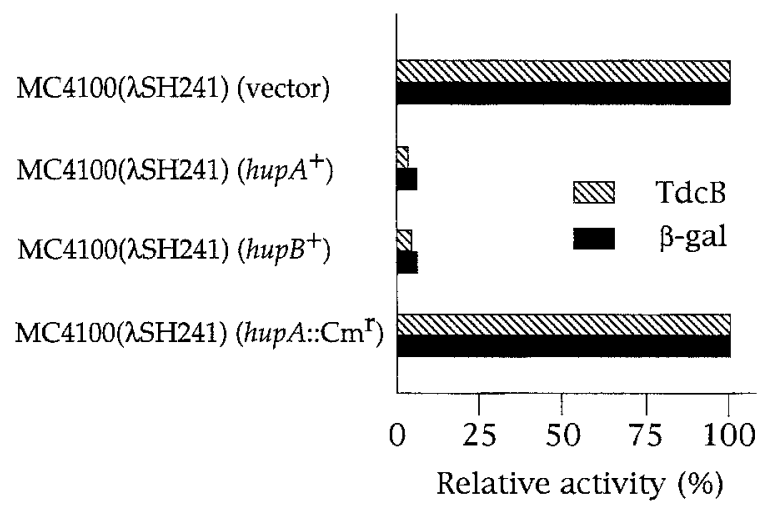

Fig. 2 Effects of multicopy hup genes on $t d c$ expression. $\beta$-Galactosidase and threonine dehydratase activities of strain MC4100( $\lambda$ SH241) transformed separately with the plasmids pYW409, pYW410 and pYW411 bearing, respectively, the cloned hupA, hupB, and hupA:: $\mathrm{Cm}^{\mathrm{r}}$ and the vector (pTrc99A) were measured as described (Miller 1992; Hobert and Datta 1983). Enzyme activities are normalized with respect to the values obtained with the vector (1787 units and 3914 units of $\beta$-galactosidase and threonine dehydratase, respectively)

and not the flanking DNA, prevented $t d c$ expression was confirmed by cloning into pTrc99AKan a 551-bp fragment encompassing hupA with its own promoter and terminator sequences (from nucleotide -57 to +494 , Kano et al. 1987), which was amplified by polymerase chain reaction (PCR) employing appropriate primers. When this $h u p A^{+}$gene fragment (pYW409) was introduced into MC4100( $\lambda S \mathrm{SH} 241$ ), both TdcB activity from the chromosome and $l a c Z$ expression from the fusion were reduced by about $90 \%$ as compared with the vector control (Fig. 2). A control experiment showed that transformation of MC4100( $\lambda \mathrm{SH} 241)$ with the plasmid pYW411

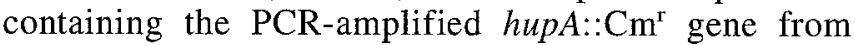
OHP109 (Huisman et al. 1989) had no effect on TdcB or LacZ levels. Therefore, a mutation that insertionally inactivates the hupA gene abolishes the hupA-mediated repression of $t d c$, and the DNA sequence cloned into the multicopy plasmid did not titrate a factor that is required for transcriptional activation of the $t d c$ promoter.
Figure 2 also shows that the plasmid pYW410, containing the PCR-amplified $h u p B^{+}$gene (from nucleotide 122 to +477 , see Kano et al. 1985) also repressed $t d c$ gene expression. Published reports indicate that the $h u$ $p A$ and $h u p B$ genes encode, respectively, HU2 and HU1 subunits of the $20-\mathrm{kDa}$, heterodimeric, basic, histonelike protein HU, (Kano et al. 1985, 1987), which affects a variety of cellular processes including replication of DNA, integrative recombination of $\lambda$ and $\mu$ phages, and transcription of certain E. coli genes (Drlica and Rouvière-Yaniv 1987; Flashner and Gralla 1988; and references therein).

It is difficult to assess the physiological role of a protein in gene regulation when it is produced in excess in the cell from multicopy plasmids. To circumvent this problem, we compared expression of chromosomal $t d c B$ in individual hup mutants with that in their isogenic counterparts, because the results described above suggested that $t d c$ expression would be partially repressed in strains harboring single-copy hup genes, and that mutants lacking hupA and/or hupB would have derepressed levels of $t d c$ gene products. For this experiment the mutant hupA and hupB genes from strains OHP109 and OHP96 (Huisman et al. 1989) were transferred into MC4100 by P1 transduction, yielding, respectively, DW109 and DW96. The hupA hupB double mutant (DW111) was constructed by P1 transduction from OHP96 into DW109. Representative results of enzyme assays given in Table 1, Expt. I show 2 to 3-fold higher $T d c B$ activities in the hupA strain and in the hupA hupB double mutant, relative to the isogenic parent. Both the protein and operon fusions of $t d c$ with lacZ (Expts. II and III, respectively) showed similar extents of derepression in the hupA strain. These results clearly suggest that a single-copy hupA gene significantly regulates $t d c$ operon expression in vivo at the level of transcription.

A marginal derepression of $t d c$ in the hupB mutant (DW96) relative to MC4100 (Table 1), seen consistently in all experiments, was not surprising. It has been previously shown that hupA cells contain HU1 homodimers and $h u p B$ strain accumulates HU2 homodimers; furthermore, the hupA gene appears to be dominant in its effect
Table $1 t d c$ gene expression in hup mutants

\begin{tabular}{|c|c|c|c|c|}
\hline Experiment & Strain & Relevant genotype & TdcB activity ${ }^{a}$ & LacZ activity ${ }^{a}$ \\
\hline I & $\begin{array}{l}\text { MC4100 } \\
\text { DW109 } \\
\text { DW96 } \\
\text { DW111 }\end{array}$ & 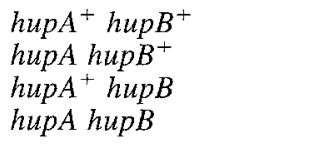 & $\begin{array}{l}2,892(1.0) \\
8,250(2.9) \\
4,137(1.4) \\
6,607(2.3)\end{array}$ & $\begin{array}{l}\text { ND } \\
\text { ND } \\
\text { ND } \\
\text { ND }\end{array}$ \\
\hline II & $\begin{array}{l}\text { MC4100( } \lambda \mathrm{SH} 241) \\
\mathrm{DW} 109(\lambda \mathrm{SH} 241)\end{array}$ & $\begin{array}{l}\text { hup } A^{+} \lambda t d c A B^{\prime}-' \text { lacZ } \\
\text { hupA } \lambda t d c A B^{\prime}-' l a c Z\end{array}$ & $\begin{array}{l}\text { ND } \\
\text { ND }\end{array}$ & $\begin{array}{l}915(1.0) \\
3,593(3.9)\end{array}$ \\
\hline III & 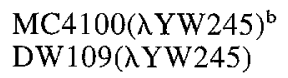 & $\begin{array}{l}\text { hupA } A^{+} \lambda t d c P-l a c Z \\
\text { hupA } \lambda t d c P-l a c Z\end{array}$ & $\begin{array}{l}3,314(1.0) \\
10,133(3.1)\end{array}$ & $\begin{array}{l}623(1.0) \\
2,109(3.4)\end{array}$ \\
\hline
\end{tabular}

${ }^{\text {a }}$ Cells were incubated anaerobically in TYE medium for $8 \mathrm{~h}$ and enzyme assays were performed according to Hobert and Datta (1983) and Miller (1992). TdcB activity is expressed as nmol of $\alpha$-ketobutyrate formed per min per $\mathrm{mg}$ of protein, and LacZ activity in Miller units. Values in parenthesis represent the activity relative to the control (1.0). ND, not determined

${ }^{\mathrm{b}}$ The $t d c$ operon fusion was constructed by cloning the $t d c P$ DNA fragment (nucleotides 1335 to 1889; Schweizer and Datta 1989a) into pRS415 (Simons et al. 1987) 
over hupB (Bonnefoy et al. 1989; Huisman et al. 1989; Hsieh et al. 1991). In view of this, it is likely that HU2 homodimers encoded by hupA ${ }^{+}$in DW96 repressed $t d c$ expression to the same extent as that seen in MC4100.

How does HU protein influence the transcriptional efficiency of the $t d c$ promoter? It has been reported that HU binds DNA non-specifically in a sequence-independent manner (Drlica and Rouvière-Yaniv 1987; Bonnefoy and Rouvière-Yaniv 1991) and bends and coils DNA into higher order structures. For example, in vitro experiments with purified HU showed that the pitch of the DNA helix in the HU-DNA complex is shortened from a repeat length of 10.5 to 8.5 bp per helical turn, due to DNA compaction (Broyles and Pettijohn 1986); also, estimates of DNA supercoil densities by gel electrophoresis of reporter plasmids isolated from hup mutants revealed reduced DNA supercoiling in cells lacking HU protein (Hsieh et al. 1991; Yusuzawa et al. 1992). Thus, it is reasonable to assume that expression of the $t d c$ operon might be sensitive to HU-mediated topological changes in the chromosomal DNA.

In order to decide whether the HU-promoted DNA structural changes indirectly influence $t d c$ expression by regulating the synthesis of Crp and/or IHF which activate transcription, we compared chromosomally encoded $\beta$-galactosidase and acetohydroxy acid synthetase (the ilvB gene product) activities in W3110 to those in the same strain transformed with the cloned $h u p A^{+}$gene. If overexpression of $\mathrm{HU}$ depleted the cells of Crp and/or IHF, it should also reduce the levels of these enzymes, because lacZ expression requires Crp (Reznikoff 1992) and the ilvBN operon is subject to regulation by both Crp and IHF (cited in Wu et al. 1992). Our results revealed no significant difference in $\beta$-galactosidase and acetohydroxy acid synthetase activities in W3110 harboring the hup $A^{+}$gene, the hupA:: $\mathrm{Cm}^{\mathrm{r}}$ plasmid and the control vector. We assume therefore that $h u p A^{+}$gene product does not influence $\mathrm{Crp}$ and IHF levels; however, we cannot completely rule out the unlikely possibility that high concentrations of HU might deplete some, as yet unknown, regulatory factor(s) essential for $t d c$ expression. It should be noted however that single-copy hupA regulates $t d c$ expression in vivo (see Table 1).

To test whether DNA topology influences $t d c$ expression, we assayed TdcB levels in $E$. coli strains harboring a combination of mutations in the genes encoding the $\mathrm{HU}$ protein, DNA gyrase and topoisomerase I. Reports in the literature indicate that in topological terms bacterial chromosomal DNA appears to exist in the negative supercoiled state, and the extent of supercoiling depends, at least partially, on the ratio of two enzyme activities, namely DNA gyrase, which introduces negative supercoils, and topoisomerase I, which relaxes the supercoiled form (reviewed by Wang 1991). Figure 3 shows that MC4100 harboring one copy each of gyrAB $B^{+}$, hupAB $B^{+}$, and top $A^{+}$genes exhibited low dehydratase activity, whereas, DW 1093 harboring mutations in gyrB and $h u$ $p A$ but containing top $A^{+}$showed an increase in $\mathrm{TdcB}$ level. Mutations in gyrB (DW4222) or in hupA (DW109)

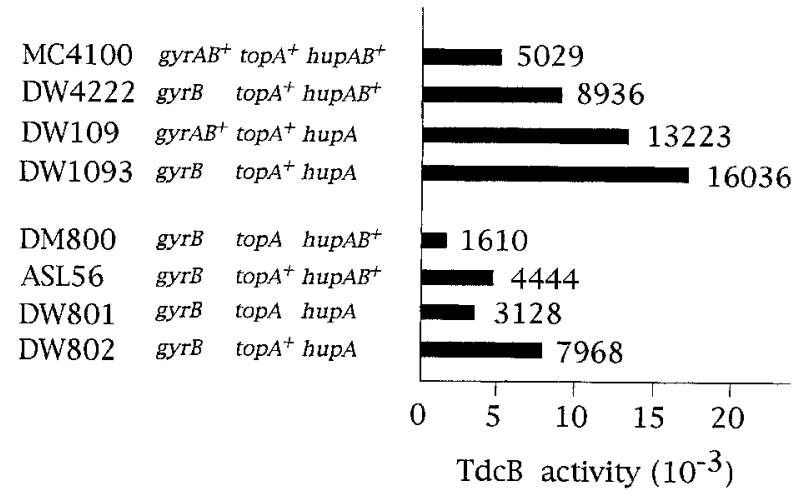

Fig. $3 \mathrm{TdcB}$ activities in strains harboring various mutations in the $g y r B$, topA, and hupA genes after anaerobic incubation for $8 \mathrm{~h}$ in TYE medium (Hobert and Datta 1983). Enzyme specific activities (nmoles of $\alpha$-ketobutyrate formed per min per mg protein) are shown next to the solid bars. DW4222 ( $\left.\mathrm{Cou}^{\mathrm{r}}\right)$ and DW1093 (Cour) are spontaneous coumermycin-resistant $(50 \mu \mathrm{g} / \mathrm{ml})$ derivatives of MC4100 and DW109, respectively. DM800 [ $\Delta$ (topA-cysB $) 204$ gyrB225 $\left.\left(\mathrm{Cou}^{\mathrm{r}}\right)\right]$ and its derivative ASL56 [topA ${ }^{+}$gyrB225 $\left.\left(\mathrm{Cou}^{\mathrm{r}}\right)\right]$ were constructed in W3110 (Sternglanz et al. 1981). DM801 (DM800 hupA) was isolated by P1 transduction from DW 109 , and DW802 [(DW801 $\left(\right.$ (top $\left.\left.^{+}\right)\right]$was constructed by cloning pJW249 top $A^{+}$(Wang and Becherer 1983) into $\lambda R Z 5$ and then recombining onto the DW801 chromosome as described (Hagewood et al. 1994). The four strains shown at the top are derivatives of $\mathrm{MC} 4100$, whereas the four strains shown at the bottom are derivatives of W3110

alone led to intermediate levels of TdcB. Similarly, in a different strain background a 5-fold higher dehydratase activity was seen in DW802 top $A^{+}$gyrB hupA as compared with DM800 topA gyrB hup $A^{+}$, whereas mutations in all three genes, gyrB, topA and hupA (DW801), caused a decrease in $\mathrm{TdcB}$ level. The same pattern of enzyme levels was seen using single-copy lac $Z$ transcriptional fusions of MC4100 derivatives (data not shown). These results are consistent with the previous report (Sumantran et al. 1989) that inhibition of DNA gyrase activity by nalidixic acid and coumermycin increases TdcB expression in E. coli $\mathrm{K} 37$.

The cumulative genetic evidence summarized above clearly shows that the transcriptional efficiency of the $t d c$ promoter in various mutants follows a common pattern: the more relaxed the DNA, the higher the level of the expression of the $t d c$ operon. These results, however, do not distinguish between changes in the global DNA topology and perturbation of local DNA structure at the $t d c$ promoter, because the HU protein and topoisomerases affect DNA structure in a sequence-independent manner. Nevertheless, it is reasonable to conclude that DNA supercoiling plays an important part in the steady-state expression of the $t d c$ operon, and that genetic and/or environmental factors that influence DNA topology are likely to modulate its transcription pattern significantly.

We showed earlier (Schweizer and Datta 1989b; Wu and Datta 1992; Wu et al. 1992; Ganduri et al. 1993) that four proteins, TdcA, TdcR, Crp and IHF, are required for $t d c$ gene expression. IHF and Crp occupy unique binding sites on $t d c P$ at positions -104 and -41 , respectively 
(with respect to transcription-start site at +1 ). These proteins, individually, induce DNA bending at $t d c P$ but cannot activate transcription. However, simultaneous binding of both proteins bends DNA into a new conformation to allow transcription to proceed. Recent experiments suggest that TdcA binds upstream from IHF at around -175, and the IHF- and Crp-mediated DNA bending allows looping of the promoter DNA to juxtapose TdcR, TdcA, and Crp into a favorable configuration, with respect to each other for transcription initiation by RNA polymerase (Hagewood et al. 1994). It is plausible then that relaxation of supercoiled DNA near the $t d c$ operon might promote an optimal configuration of the protein-DNA complex by adjusting the phasing and/or relative spacing of the protein binding sites on the DNA for enhanced transcription. On the other hand, compaction of DNA adjacent to the $t d c$ region might disrupt the correct placement of the protein-DNA complex to an extent that prevents transcription. Alternatively, changes in global DNA topology might somehow indirectly regulate $t d c$ transcription. Whatever the exact mechanism may be, it is evident that regulation of $t d c$ gene expression by the operon-specific transcriptional factors, TdcR and $\mathrm{TdcA}$, is greatly influenced by the global regulatory proteins $\mathrm{HU}$ and topoisomerases, which alter overall DNA topology, and by IHF and Crp, which promote bending and/or looping of the $t d c$ promoter region. In view of this, the roles of transcription factors in gene expression in general must be viewed in the larger context of DNA structure and dynamics at or near the site of the target operon.

Acknowledgements We thank J. Rouvière-Yaniv, J. C. Wang, and $\mathrm{H}$. Zalkin for providing bacterial strains and plasmids. We also thank B. Hagewood and Y. Ganduri for many stimulating discussions. This work was supported by Grant GM21436 from the National Institutes of Health. Computer facilities supported by NIH Grant M01 RR00042 were provided by the General Clinical Research Center, University of Michigan Medical School.

\section{References}

Bonnefoy E, Rouvière-Yaniv J (1991) HU and IHF, two homologous histone-like proteins of Escherichia coli, form different protein-DNA complexes with short DNA fragments. EMBO J 10:687-696

Bonnefoy E, Almeida A, Rouvière-Yaniv J (1989) Lon-dependent regulation of the DNA binding protein $\mathrm{HU}$ in Escherichia coli. Proc Natl Acad Sci USA 86: 7691-7695

Broyles SS, Pettijohn DE (1986) Interaction of the Escherichia coli $\mathrm{HU}$ protein with DNA. Evidence for formation of nucleosome-like structures with altered DNA helical pitch. J Mol Biol 187:47-60

Drlica K, Rouvière-Yaniv J (1987) Histonelike proteins of bacteria. Microbiol Rev 51:301-319

Flashner Y, Gralla JD (1988) DNA dynamic flexibility and protein recognition: differential stimulation by bacterial histone-like protein HU. Cell 54:713-721
Ganduri YL, Sadda SR, Datta MW, Jambukeswaran RK, Datta P (1993) TdcA, a transcriptional activator of the $t d c A B C$ operon of Escherichia coli, is a member of the LysR family of proteins. Mol Gen Genet 240:395-402

Goss TJ, Schweizer HP, Datta P (1988) Molecular characterization of the $t d c$ operon of Escherichia coli K-12. J Bacteriol 170:5352-5359

Hagewood BT, Ganduri YL, Datta P (1994) Functional analysis of the $t d c A B C$ promoter of Escherichia coli: roles of TdcA and TdcR. J Bacteriol 176: 6214-6220

Hobert EH, Datta P (1983) Synthesis of biodegradative threonine dehydratase of Escherichia coli: role of amino acids, electron acceptors, and certain intermediary metabolites. J Bacteriol 155:586-592

Hsieh L-S, Rouvière-Yaniv J, Drlica K (1991) Bacterial DNA supercoiling and $[\mathrm{ATP}] /[\mathrm{ADP}]$ ratio: changes associated with salt shock. J Bacteriol 173:3914-3917

Huisman O, Faelen M, Girard D, Jaffe A, Toussant A, RouvièreYaniv J (1989) Multiple defects in Escherichia coli mutants lacking HU protein. J Bacteriol 171:3704-3712

Kano Y, Yoshino S, Wada M, Yokoyama K, Nobuhara M, Imamoto $F$ (1985) Molecular cloning and nucleotide sequence of the HU-1 gene of Escherichia coli. Mol Gen Genet 201:360-362

Kano Y, Osato K, Wada M, Imamoto F (1987) Cloning and sequencing of the HU-2 gene of Escherichia coli. Mol Gen Genet 209: 408-410

Miller JH (1992) A short course in bacterial genetics. Cold Spring Harbor Laboratory Press, Cold Spring Harbor, New York

Reznikoff WS (1992) Catabolite gene activator protein activation of lac transcription. J Bacteriol 174:655-658

Schweizer HP, Datta P (1989a) The complete nucleotide sequence of the $t d c$ region of Escherichia coli. Nucleic Acids Res $17: 3994$

Schweizer HP, Datta P (1989b) Identification and DNA sequence of $t d c R$, a positive regulatory gene of the $t d c$ operon of $E_{S-}$ cherichia coli. Mol Gen Genet 218:516-522

Simons RW, Houman F, Kleckner N (1987) Improved single and multicopy lac-based cloning vectors for protein and operon fusions. Gene 53:85-96

Sternglanz R, DiNardo S, Voelkel KA, Nishimura Y, Hirota Y, Becherer K, Zumstein L, Wang JC (1981) Mutations in the gene coding for Escherichia coli DNA topoisomerase I affect transcription and transposition. Proc Natl Acad Sci USA $78: 2747-2751$

Sumantran VN, Schweizer HP, Datta P (1990) A novel membraneassociated threonine permease encoded by the $t d c C$ gene of Escherichia coli. J Bacteriol 172:4288-4294

Sumantran VN, Tranguch AJ, Datta P (1989) Increased expression of biodegradative threonine dehydratase of Escherichia coli by DNA gyrase inhibitors. FEMS Microbiol Lett 65:37-40

Wang JC (1991) DNA topoisomerases: Why so many? J Biol Chem 266:6659-6662

Wang JC, Becherer K (1983) Cloning of the gene topA encoding for DNA topoisomerase I and the physical mapping of the $c y s B$ topA-trp region of Escherichia coli. Nucleic Acids Res 11: $1773-1790$

Wu Y, Datta P (1992) Integration host factor is required for positive regulation of the $t d c$ operon of Escherichia coli. $\mathrm{J}$ Bacteriol 174: 233-240

Wu Y, Patil RV, Datta P (1992) Catabolite gene activator protein and integration host factor act in concert to regulate $t d c$ operon expression in Escherichia coli. J Bacteriol 174:6918-6927

Yusuzawa K, Hayashi N, Goshima N, Kohno K, Imamoto F, Kano $Y$ (1992) Histone-like proteins are required for cell growth and constraint of supercoils in DNA. Gene 122:9-15 